University of Nebraska - Lincoln

DigitalCommons@University of Nebraska - Lincoln

Faculty Papers and Publications in Animal

Science

Animal Science Department

April 1999

\title{
Variance Components and Breeding Values for Growth Traits from Different Statistical Models
}

\author{
G. B. Ferreira \\ University of Nebraska-Lincoln
}

M. D. MacNeil

USDA, ARS, Livestock and Range Research Lab, Miles City, MT

L. Dale Van Vleck

University of Nebraska-Lincoln, dvan-vleck1@unl.edu

Follow this and additional works at: https://digitalcommons.unl.edu/animalscifacpub

Part of the Animal Sciences Commons

Ferreira, G. B.; MacNeil, M. D.; and Van Vleck, L. Dale, "Variance Components and Breeding Values for Growth Traits from Different Statistical Models" (1999). Faculty Papers and Publications in Animal Science. 285.

https://digitalcommons.unl.edu/animalscifacpub/285

This Article is brought to you for free and open access by the Animal Science Department at DigitalCommons@University of Nebraska - Lincoln. It has been accepted for inclusion in Faculty Papers and Publications in Animal Science by an authorized administrator of DigitalCommons@University of Nebraska - Lincoln. 


\title{
Variance Components and Breeding Values for Growth Traits from Different Statistical Models ${ }^{1}$
}

\author{
G. B. Ferreira ${ }^{*, 2,3}$, M. D. MacNeil $\dagger$, and L. D. Van Vleck \\ *Department of Animal Science, University of Nebraska, Lincoln 68583-0908 and USDA, ARS, †Livestock and \\ Range Research Lab, Miles City, MT 59301 and $\ddagger$ Roman L. Hruska U.S. Meat Animal Research Center, \\ Lincoln, NE 68583-0908
}

\begin{abstract}
Estimates of genetic parameters resulting from various analytical models for birth weight (BWT, $\mathrm{n}=4,155$ ), 205-d weight (WWT, $\mathrm{n}=3,884$ ), and 365 -d weight (YWT, $\mathrm{n}=3,476$ ) were compared. Data consisted of records for Line 1 Hereford cattle selected for postweaning growth from 1934 to 1989 at ARSUSDA, Miles City, MT. Twelve models were compared. Model 1 included fixed effects of year, sex, age of dam; covariates for birth day and inbreeding coefficients of animal and of dam; and random animal genetic and residual effects. Model 2 was the same as Model 1 but ignored inbreeding coefficients. Model 3 was the same as Model 1 and included random maternal genetic effects with covariance between direct and maternal genetic effects, and maternal permanent environmental effects. Model 4 was the same as Model 3 but ignored inbreeding. Model 5 was the same as Model 1 but with a random sire effect instead of animal genetic effect. Model 6 was the same as Model 5 but ignored inbreeding. Model 7 was a sire model that considered relationships among males. Model 8 was a sire model, assuming sires to be unrelated, but with dam effects as uncorrelated random effects to account for maternal effects.
\end{abstract}

Model 9 was a sire and dam model but with relationships to account for direct and maternal genetic effects; dams also were included as uncorrelated random effects to account for maternal permanent environmental effects. Model 10 was a sire model with maternal grandsire and dam effects all as uncorrelated random effects. Model 11 was a sire and maternal grandsire model, with dams as uncorrelated random effects but with sires and maternal grandsires assumed to be related using male relationships. Model 12 was the same as Model 11 but with all pedigree relationships from the full animal model for sires and maternal grandsires. Rankings on predictions of breeding values were the same regardless of whether inbreeding coefficients for animal and dam were included in the models. Heritability estimates were similar regardless of whether inbreeding effects were in the model. Models 3 and 9 best fit the data for estimation of variances and covariances for direct, maternal genetic, and permanent environmental effects. Other models resulted in changes in ranking for predicted breeding values and for estimates of direct and maternal heritability. Heritability estimates of direct effects were smallest with sire and sire-maternal grandsire models.

Key Words: Genetic Parameters, Growth, Statistics

(C1999 American Society of Animal Science. All rights reserved.

J. Anim. Sci. 1999. 77:2641-2650

\section{Introduction}

Growth traits in beef cattle are important in selection programs. The relative importance of direct and maternal additive genetic effects for growth should be considered when beef producers formulate breeding plans.

\footnotetext{
${ }^{1}$ Published as paper no. 12359, Journal Ser., Nebraska Agric. Res. Div., Univ. of Nebraska, Lincoln 68583-0908. This study was conducted while the first author was a graduate student at Univ. of Nebraska, with financial support of Conselho Nacional de Desenvolvimento Científico e tecnológico (CNPq) and Universidade Federal de Santa Maria, RS-Brazil.

Received August 31, 1998.

Accepted April 26, 1999.
}

Increased computing power and software capability have facilitated the use of more detailed models and more sophisticated statistical procedures to estimate variance components and predict breeding values. In addition to a sire model, it is possible to use an animal model with or without maternal effects, a sire-dam model, or a sire-maternal grandsire model. Comparisons among results from different statistical models

\footnotetext{
${ }^{2}$ Current address: Departamento de Zootecnia, UFSM, 97119-900 Santa Maria-RS-Brazil.

${ }^{3}$ To whom correspondence should be addressed: Departamento de Zootecnia, UFSM, 97119-900 Santa Maria-RS-Brazil (phone: (055)220-8268; fax: (055)220-8692; E-mail: gbbf@ccr.ufsm.br).
} 
Table 1. Descriptive statistics for records for birth weight (BWT), weaning weight (WWT), and yearling weight (YWT)

\begin{tabular}{|c|c|c|c|c|c|}
\hline Item & BWT & WWT & YWT & YWT( ڤิ) & YWT( $(q)$ \\
\hline \multicolumn{6}{|l|}{ Weight, kg } \\
\hline Mean & 35.9 & 202.5 & 313.8 & 393.6 & 255.5 \\
\hline Standard deviation & 4.7 & 30 & 80.0 & 40.8 & 42.5 \\
\hline Coefficient of variation, $\%$ & 13.1 & 14.8 & 25.5 & 10.4 & 16.5 \\
\hline \multicolumn{6}{|l|}{ Inbreeding (fraction) } \\
\hline Calf mean & .23 & .22 & .22 & .23 & .22 \\
\hline Calf range & 0 to .46 & 0 to .46 & 0 to .46 & 0 to .43 & 0 to .46 \\
\hline Dam mean & .20 & .19 & .19 & .20 & .15 \\
\hline Dam range & 0 to .44 & 0 to .44 & 0 to .44 & 0 to .44 & 0 to .44 \\
\hline Numbers $^{\mathrm{a}}$ & 4,155 & 3,884 & 3,476 & 1,467 & 2,009 \\
\hline
\end{tabular}

${ }^{\text {a}}$ Number of years, 55; sexes, 2; age of dam classes, 9; sires, 160; maternal grandsires, 161.

can be used to determine their strengths and weaknesses and to determine whether simpler computational models may be adequate. The use of inbreeding coefficients and more complex models for prediction of breeding values can substantially increase the computational requirements. The objectives of this research were to compare estimates of variance components and predictions of breeding value for birth weight (BWT), weaning weight (WWT), and yearling weight (YWT) from Hereford beef cattle using different statistical models to determine whether simpler models produce estimates similar to those produced by more complex alternatives. The uniqueness of the data, which included only one closed herd, allowed investigation of whether an increase in inbreeding from 1935 to 1989 affected estimates of variance components and whether inbreeding needs to be considered for ranking of animals based on predicted breeding values.

\section{Materials and Methods}

\section{Description of the Data}

The data used were 4,155 birth weight (BWT), 3,884 weaning weight (adjusted to $205 \mathrm{~d}$, WWT) and 3,476 yearling weight (adjusted to $365 \mathrm{~d}$, YWT) records for Hereford beef cattle from the Line 1 project conducted at the Fort Keogh Livestock and Range Research Laboratory (LARRL) in Miles City, MT. Lines developed at LARRL were begun in 1934 with the first calves in Line 1. Two sons of Advance Domino 13th, Advance Domino 20th, and Advance Domino 54th were the primary foundation sires of Line 1 (MacNeil et al., 1992).

Table 1 lists descriptive statistics of the records for the three traits evaluated. The means were averaged over all years. Cows were 2 through $15 \mathrm{yr}$ of age at calving. Ages at calving of 10,11,12,13,14, and $15 \mathrm{yr}$ were grouped together in the class for $10 \mathrm{yr}$ of age. The numbers of levels for years, sexes, and ages of dam were the same for the three traits. Records of animals with birth, weaning, and yearling weights outside the range of three unadjusted phenotypic standard deviations were deleted from the analyses.
Inbreeding coefficients were calculated for animals and for dams. The means of inbreeding coefficients for animals and dams were essentially the same for all three traits analyzed. The numbers of sires and maternal grandsires (MGS) were the same for the three traits.

\section{Models}

Each trait was analyzed separately with 12 models. Model 1 was the simplest animal model. Model 3 was the most complete animal model. Models 2 and 4 did not include covariates for inbreeding of animal and dam, whereas Models 1 and 3 did. Models 5 to 12 began with the simplest sire model and increased in complexity to Model 11. The equation for Model 3 for a single trait was as follows:

$$
\mathbf{y}=\mathbf{X} \boldsymbol{\beta}+\mathbf{Z g}+\mathbf{M m}+\mathbf{W} \mathbf{p}+\mathbf{e}
$$

where:

$\mathbf{y}$ is a vector of observations;

$\boldsymbol{\beta}$ is a vector of fixed effects (year of birth, sex, age of dam, and covariates for day of birth from January 1 , inbreeding coefficient of animal and inbreeding coefficient of its dam);

$\mathbf{g}$ is a vector of random additive direct genetic effects;

$\mathbf{m}$ and $\mathbf{p}$ are vectors of random maternal genetic and permanent environmental effects;

$\mathbf{e}$ is a vector of random residual effects; and

$\mathbf{X}, \mathbf{Z}, \mathbf{M}$, and $\mathbf{W}$ are known incidence matrices relating observations to the respective fixed and random effects with $\mathbf{Z}$ and $\mathbf{M}$ augmented with columns of zeros for animals without records and for animals that were not dams that were included in the relationship matrices. The first and the second moments of the model were assumed to be:

$$
\mathrm{E}\left[\begin{array}{l}
\mathbf{y} \\
\mathbf{g} \\
\mathbf{m} \\
\mathbf{p} \\
\mathbf{e}
\end{array}\right]=\left[\begin{array}{l}
\mathbf{X} \boldsymbol{\beta} \\
\mathbf{0} \\
\mathbf{0} \\
\mathbf{0} \\
\mathbf{0}
\end{array}\right] ; \quad \operatorname{Var}\left[\begin{array}{l}
\mathbf{g} \\
\mathbf{m} \\
\mathbf{p} \\
\mathbf{e}
\end{array}\right]=\left[\begin{array}{llll}
\mathbf{A} \sigma_{\mathrm{g}}^{2} & \mathbf{A} \sigma_{\mathrm{gm}} & 0 & 0 \\
\mathbf{A} \sigma_{\mathrm{gm}} & \mathbf{A} \sigma_{\mathrm{m}}^{2} & 0 & 0 \\
0 & 0 & \mathbf{I}_{\mathrm{nc}} \sigma_{\mathrm{p}}^{2} & 0 \\
0 & 0 & 0 & \mathbf{I}_{\mathrm{n}} \sigma_{\mathrm{e}}^{2}
\end{array}\right]
$$




$$
\begin{gathered}
\mathrm{V}(\mathbf{y})=\mathbf{Z A Z} \mathbf{Z}^{\prime} \sigma_{\mathrm{a}}^{2}+\mathbf{Z A M}^{\prime} \sigma_{\mathrm{gm}}+\mathbf{M A Z} \mathbf{Z}^{\prime} \sigma_{\mathrm{gm}}+\mathbf{M} \mathbf{A} \mathbf{M}^{\prime} \sigma_{\mathrm{m}}^{2} \\
+\mathbf{W} \mathbf{W}^{\prime} \sigma_{\mathrm{p}}^{2}+\mathbf{I}_{\mathrm{n}} \sigma_{\mathrm{e}}^{2} .
\end{gathered}
$$

where

$\sigma_{\mathrm{a}}^{2}$ is the direct additive genetic variance;

$\sigma_{\mathrm{m}}^{2}$ and $\sigma_{\mathrm{p}}^{2}$ are the maternal additive genetic and permanent environmental variances;

$\sigma_{\mathrm{am}}$ is the covariance between additive direct and additive maternal genetic effects;

$\sigma_{\mathrm{e}}^{2}$ is the residual variance, in this case, $\sigma_{\text {te }}^{2}$, temporary environmental variance;

$\mathbf{I}_{\mathrm{nc}}$ and $\mathbf{I}_{\mathrm{n}}$ are identity matrices of order equal to the number of dams (nc) and to the total number of animals with records (n), respectively; and

$\mathbf{A}$ is the additive numerator relationship matrix with order $\mathbf{q}$.

The inverse of $\mathbf{A}$ was calculated using the rules of Quaas (1976) including ancestors of animals with records.

\section{Estimation of (co)Variance Components}

Variance components were estimated with derivative-free REML (Graser et al., 1987; Meyer, 1989) using multiple-trait derivative-free restricted maximum likelihood (MTDFREML) programs (Boldman et al., 1995). The method involves maximizing the likelihood function $(\Lambda)$ given the data and is the same as maximizing $\log \Lambda$ or minimizing $-2 \log \Lambda$.

Iterations were stopped when the variance of function values $(-2 \log \Lambda)$ in the simplex were less than $1 \times 10^{-6}$. Each analysis was then restarted using the resulting estimates of the parameters as new priors until changes in the function value and estimates of the scaled parameters (variances as proportions of phenotypic variance and correlations) were less than .01 .

Comparisons of the different models were made with likelihood-ratio tests. The difference between the function values for pairs of models can be tested against the chi-square distribution with degrees of freedom being the difference in number of variance or covariance components in the models (e.g., Dobson, 1990). Whether animal and sire models can be compared this way is not clear because, for example, the simple animal and sire models would both contain two variance components.

All models contained the same fixed effects except when covariates for inbreeding coefficients of animal and dam were ignored.

Model 3 was the full animal model including covariates for inbreeding of animals and dams. Model 1 was the same as Model 3 but without the maternal genetic and permanent effects. Model 2 was the same as Model 1 but with effects of inbreeding ignored. Model 4 was the same as Model 3 but without covariates for inbreeding of animal and dam. Model 5 was a sire model with inbreeding coefficients for animals and dams, consider- ing sires to be unrelated. Model 6 was the same as Model 5 but without the inbreeding coefficients. Model 7 was a sire model without the inbreeding coefficients, but, in this case, using relationships through sires calculated using sires of sires and maternal grandsire of sires (Henderson, 1975). Model 8 was also a sire model, assuming sires to be unrelated and with dams assumed to be associated with uncorrelated random effects to account for maternal effects. Model 9 was a sire and dam model, using all pedigree relationships from the full animal model, to account for direct and maternal genetic effects with dams also used to indicate uncorrelated random effects (c) to account for maternal permanent environmental effects. Model 10 included sire, dam, and MGS effects as uncorrelated random effects (no relationships considered) with the dam effect to account for maternal genetic effects not accounted for by the MGS effects as well as for maternal permanent environmental effects. Model 11 was a sire and MGS model, with dams as uncorrelated random effects but with sires and maternal grandsires assumed to be related with relationships through males using males, sires of males, and MGS of males. Model 12 was the same as Model 11 but using all pedigree relationships from the full animal model for sires and maternal grandsires. For yearling weight, Model 12 was also used for separate analyses for measurements on males and females separately and also for a two trait (by sex) analysis because of evidence of differences between sexes for variances and fixed effects (Garrick et al., 1989; Robert M. Koch, personal communication).

With these models, the interpretation of the component of variance for uncorrelated effects of dams will vary depending on the other parts of the model. For example, for the full animal model, the component for dam effects is a measure of variance due to maternal permanent environmental effects, whereas for the model with uncorrelated sire and dam effects (Model 8), the dam component accounts for maternal genetic and permanent environmental effects. Table 2 shows the basic differences in the models.

To retrieve estimates of causal variance components from estimates of model components for sire, sire and dam, and sire-MGS models, model components were decomposed as follows:

For sire model:

$$
\begin{aligned}
& \sigma_{\mathrm{s}}^{2}=1 / 4 \sigma_{\mathrm{g}}^{2} \\
& \sigma_{\mathrm{e}}^{2}=(3 / 4) \sigma_{\mathrm{g}}^{2}+\sigma_{\mathrm{m}}^{2}+\sigma_{\mathrm{gm}}+\sigma_{\mathrm{p}}^{2}+\sigma_{\mathrm{te}}^{2}
\end{aligned}
$$

For sire-dam model:

$$
\begin{aligned}
\sigma_{\mathrm{s}}^{2}= & (1 / 4) \sigma_{\mathrm{g}}^{2}, \\
\sigma_{\mathrm{d}}^{2}= & (1 / 4) \sigma_{\mathrm{g}}^{2}+\sigma_{\mathrm{m}}^{2}+\sigma_{\mathrm{gm}},\left(\text { plus } \sigma_{\mathrm{p}}^{2}\right. \text { when relation- } \\
& \text { ships among sires and dams were ig- } \\
& \text { nored). } \\
\sigma_{\mathrm{s}, \mathrm{d}}= & (1 / 4) \sigma_{\mathrm{g}}^{2}+(1 / 2) \sigma_{\mathrm{gm}}, \quad \text { (when relationships } \\
& \text { among sires and dams were used), }
\end{aligned}
$$


Table 2. Summary of models ${ }^{a}$

\begin{tabular}{lcccccccccccc}
\hline \hline & \multicolumn{110}{c}{ Model } \\
\cline { 2 - 11 } Item & 1 & 2 & 3 & 4 & 5 & 6 & 7 & 8 & 9 & 10 & 11 & 12 \\
\hline Inbreeding & Y & - & Y & - & Y & - & Y & Y & Y & Y & Y & Y \\
Animal genetic & $\mathrm{A}$ & A & A & A & - & - & - & - & - & - & - & - \\
Maternal genetic & - & - & A & A & - & - & - & - & - & - & - & - \\
Maternal PE & - & - & Y & Y & - & - & - & - & - & - & - & - \\
Sire genetic & - & - & - & - & I & I & S & S & A & I & S & A \\
Dam total & - & - & - & - & - & - & - & I & - & - & - & - \\
Dam genetic & - & - & - & - & - & - & - & - & A & - & - & - \\
Dam PE & - & - & - & - & - & - & - & - & Y & - & - & - \\
MGS genetic & - & - & - & - & - & - & - & - & - & I & S & A \\
Dam|MGS & - & - & - & - & - & - & - & - & - & I & I & I \\
\hline
\end{tabular}

${ }^{\text {a}}$ Fixed effects of year, sex, and age of dam in all models; Y indicates included and dash indicates not included; A indicates use of all pedigree relationships; $\mathrm{S}$ indicates use of relationships through males only; I indicates relationships ignored; PE is permanent environmental effects; MGS is maternal grandsire.

$\sigma_{\mathrm{c}}^{2}=\sigma_{\mathrm{p}}^{2} \quad$ (not included when relationships among sires and dams were ignored).

$\sigma_{\mathrm{e}}^{2}=(1 / 2) \sigma_{\mathrm{g}}^{2}+\sigma_{\mathrm{te}}^{2}$;

For sire-MGS model:

$$
\begin{aligned}
\sigma_{\mathrm{s}}^{2}= & (1 / 4) \sigma_{\mathrm{g}}^{2} \\
\sigma_{\mathrm{mgs}}^{2}= & (1 / 16) \sigma_{\mathrm{g}}^{2}+(1 / 4) \sigma_{\mathrm{m}}^{2}+(1 / 4) \sigma_{\mathrm{gm}}, \text { and } \\
\sigma_{\mathrm{s}, \mathrm{mgs}}= & (1 / 8) \sigma_{\mathrm{g}}^{2}+(1 / 4) \sigma^{\mathrm{gm}}, \quad \text { (when relationships } \\
& \text { among sires and MGS were used). } \\
\sigma_{\mathrm{c}}^{2}= & (3 / 16) \sigma_{\mathrm{g}}^{2}+(3 / 4) \sigma_{\mathrm{m}}^{2}+(3 / 4) \sigma_{\mathrm{gm}}+\sigma_{\mathrm{p}}^{2} \\
\sigma_{\mathrm{e}}^{2}= & (1 / 2) \sigma_{\mathrm{g}}^{2}+\sigma_{\mathrm{te}}^{2}
\end{aligned}
$$

where

$$
\begin{array}{rr}
\sigma_{\mathrm{s}}^{2} \text { is the variance of sire effects, } \\
\sigma_{\mathrm{d}}^{2} \text { is the variance of dam within MGS effects, } \\
\sigma_{\mathrm{s}, \mathrm{d}} \text { is the covariance between effects as sires } \\
\text { and as dams, } \\
\sigma_{\mathrm{mgs}}^{2} \text { is } \begin{aligned}
\text { the variance of maternal grandsire ef- } \\
\text { fects, }
\end{aligned} \\
\sigma_{\mathrm{s}, \mathrm{mgs}} \text { is } \begin{aligned}
\text { the covariance between effects of males } \\
\text { as sires and as maternal grandsires, }
\end{aligned} \\
\sigma_{\mathrm{c}}^{2} \text { is } \begin{array}{l}
\text { the variance of permanent maternal en- } \\
\text { vironmental effects for sire and dam }
\end{array} \\
\text { models and variance of maternal (dam) } \\
\text { effects not accounted for by MGS effects } \\
\text { for sire-MGS model, } \\
\sigma_{\mathrm{te}}^{2} \text { is the variance of temporary environmen- } \\
\text { tal effects, and } \\
\sigma_{\mathrm{e}}^{2} \text { is the variance of environmental effects. }
\end{array}
$$

Simple and rank correlations were calculated between estimates of breeding values from Models 3 and 4 using all animals to compare considering and ignoring inbreeding. Correlations were also estimated between estimates of breeding values from the complete animal model (Model 3) with various sire models (Models 5, 7, 9 , and 11).

\section{Results and Discussion}

\section{Effects of Inbreeding on Estimates of Variance Components and on Estimates of Breeding Values}

When significant inbreeding exists, procedures to obtain relationship matrices that account for this effect should be implemented (Quaas, 1976; Smith and MäkiTanila, 1990; de Boer and Hoeschele, 1993). In this study, the effects of inbreeding of animals and dams were accounted for in Models 1, 3, and 5 (with inbreeding) but not in comparable Models 2, 4, and 6 (without inbreeding). Table 3 shows the heritability estimates and the log likelihoods for models with and without inbreeding. There were differences in the log likelihoods, but heritability estimates were the same regardless of whether inbreeding effects were included in the model.

The inbreeding coefficients for Line 1 increased rapidly in the late 1930 s and early 1940 s, but, since that time, inbreeding has increased at a slower rate due to avoidance of mating between close relatives. Since 1960, inbreeding has accumulated at a nearly constant annual rate of $.22 \%$ (MacNeil et al., 1992). Table 4 shows the regression coefficients for Model 3 for calendar year birth day and inbreeding coefficients of animals and dams. The regression coefficients for the inbreeding covariates show how many kilograms are lost or gained if the inbreeding coefficient increases from 0 to 1 .

Correlations between estimates of breeding values and rank correlations between ranks of animals for all traits using estimates from the full animal model, either including inbreeding effects as covariates or ignoring inbreeding effects, were near unity (.997 to .998) for all traits analyzed; almost all of the same animals would be selected if models with and without inbreeding as covariates were used for genetic evaluation.

\section{Birth Weight}

Table 5 shows the estimates of fractional model and causal components of variance and covariance for birth 
Table 3. Estimates of genetic parameters and $-2 \log$ likelihoods for analyses of birth weight (BWT), weaning weight (WWT), and yearling weight (YWT) for animal models with and without inbreeding coefficients $(\mathrm{F})$ for animals and dams and with and without relationship matrix $(\mathrm{A}$ and $\mathrm{A}=\mathrm{I})$ for sire models

\begin{tabular}{|c|c|c|c|c|c|c|}
\hline \multirow[t]{3}{*}{ Item $^{\mathrm{a}}$} & \multicolumn{6}{|c|}{ Model } \\
\hline & \multicolumn{3}{|c|}{ Model 1 (Animal Direct, A, F) } & \multicolumn{3}{|c|}{ Model 2 (Animal Direct, A) } \\
\hline & BWT & WWT & YWT & BWT & WWT & YWT \\
\hline $\mathrm{h}^{2}$ (direct) & .49 & .35 & .36 & .49 & .35 & .37 \\
\hline \multirow[t]{3}{*}{$-2 \log L$} & 15,303 & 27,675 & 26,040 & 15,322 & 27,701 & 26,065 \\
\hline & \multicolumn{3}{|c|}{ Model 3 (Full Animal, A, F) } & \multicolumn{3}{|c|}{ Model 4 (Full Animal, A) } \\
\hline & BWT & WWT & YWT & BWT & WWT & YWT \\
\hline $\mathrm{h}^{2}$ (direct) & .35 & .18 & .30 & .35 & .18 & .31 \\
\hline $\mathrm{h}^{2}$ (maternal) & .14 & .17 & .08 & .14 & .17 & .09 \\
\hline $\operatorname{cor}(\mathrm{g}, \mathrm{m})$ & -.05 & -.34 & -.26 & -.06 & -.33 & -.29 \\
\hline \multirow[t]{3}{*}{$-2 \log L$} & 15,207 & 27,341 & 25,939 & 15,224 & 27,369 & 25,955 \\
\hline & \multicolumn{3}{|c|}{ Model 5 (Sire Model A = I, F) } & \multicolumn{3}{|c|}{ Model $6($ Sire Model A = I) } \\
\hline & BWT & WWT & YWT & BWT & WWT & YWT \\
\hline $\mathrm{h}^{2}$ (direct) & .28 & .16 & .30 & .28 & .16 & .31 \\
\hline$-2 \log \mathrm{L}$ & 15,574 & 27,805 & 26,139 & 15,590 & 27,827 & 26,165 \\
\hline
\end{tabular}

${ }^{\mathrm{a}} \mathrm{h}^{2}($ direct $)=$ direct heritability; $\mathrm{h}^{2}($ maternal $)=$ maternal heritability; cor $(\mathrm{g}, \mathrm{m})=$ correlation between direct and maternal genetic effects; $-2 \log \mathrm{L}=-2 \log$ likelihood (except for a constant).

weight. Comparison of estimates for Models 1 and 3 shows that with inclusion of maternal genetic effects with genetic correlation between direct and maternal effects, and maternal permanent environmental effects, there was a decrease in the estimate of direct heritability from .49 to .35 . The likelihood-ratio test showed a significant difference $(P<.01)$ between Models 1 and 3 for BWT. Estimates agree with Koch (1972) that genetic and permanent environmental components of maternal ability and covariance of individual and maternal effects account for 15 to $20 \%$ of variation in birth weight. Estimate of the direct-maternal genetic covariance component was negative and suggests an antagonistic relationship between direct and maternal genetic effects, in agreement with the review of Robison (1981). On the whole, estimates of heritability and relative variance due to maternal permanent environmental effects for Model 3 were well within the range of comparable literature values (e.g., Meyer, 1993; Waldron et al., 1993).

The log likelihoods showed a better fit with the full model (Model 3) than with the sire model (Model 5). The heritability estimate for direct effects dropped from .35 to .27 when the sire model (Model 5) rather than

Table 4. Regression coefficients and standard errors for calendar day of birth, fractional inbreeding coefficient $(\mathrm{F})$ of calf, and fractional inbreeding coefficient of dam for birth weight (BWT), weaning weight (WWT), and yearling weight (YWT)

\begin{tabular}{lrrr}
\hline \hline Covariate & \multicolumn{1}{c}{ BWT } & \multicolumn{1}{c}{ WWT } & \multicolumn{1}{c}{ YWT } \\
\hline Calendar birth day, kg/d & $.03 \pm .04$ & $-.18 \pm .02$ & \multicolumn{1}{c}{$-.23 \pm .02$} \\
Inbreeding of calf, kg/100F & $-4.0 \pm 1.7$ & $-36.8 \pm 9.6$ & $-51.2 \pm 12.3$ \\
Inbreeding of dam, kg/1.00F & $5.1 \pm 1.6$ & $-11.7 \pm 9.5$ & $-.4 \pm 13.3$ \\
\hline
\end{tabular}

the full animal model (Model 3) was used. When sires were related (Model 7), accounted for by the relationships calculated with rules for sires, sires of sires, and maternal grandsires of sires, the heritability estimate of direct effects was .32 , which was greater than for Model 5 but less than for Model 3.

For Model 8, a sire model (assuming sires unrelated) with an uncorrelated dam effect to account for maternal environmental and genetic effects, estimate of heritability was similar to that for Model 5 (.26 vs .27). Compared with Model 3, heritability estimate of direct effects dropped to .26 from .35. The likelihood-ratio test showed significant differences between Models 5 and 8 $(P<.01)$.

Heritability estimate of direct effects was similar (.35 vs .34) for Model 3 and the sire-dam model with full pedigree information and with dam also included as indicator of uncorrelated maternal permanent environmental effects (Model 9). Estimate of maternal heritability was somewhat greater for Model 9 than for Model 3 (.20 vs .14). Estimates of genetic correlation between direct and maternal effects were negative with both models: -.05 for the full model and -.20 for the siredam model. These results suggest that maternal genetic variance and magnitude of negative correlation between direct-maternal genetic effects may have been overestimated when a sire and a dam model was used compared with a full animal model. Estimates of relative variance due to maternal permanent environmental effects were similar, .04 for Model 3 and .02 for Model 9, as were estimates of relative variance due to the sum of all maternal effects, .17 for both models.

Comparison between Model 10 (sire model with MGS and dam as uncorrelated random effects) and Model 3 showed that the heritability estimate decreased from 
Table 5. Model and causal estimates as fractions of total variance for birth weight

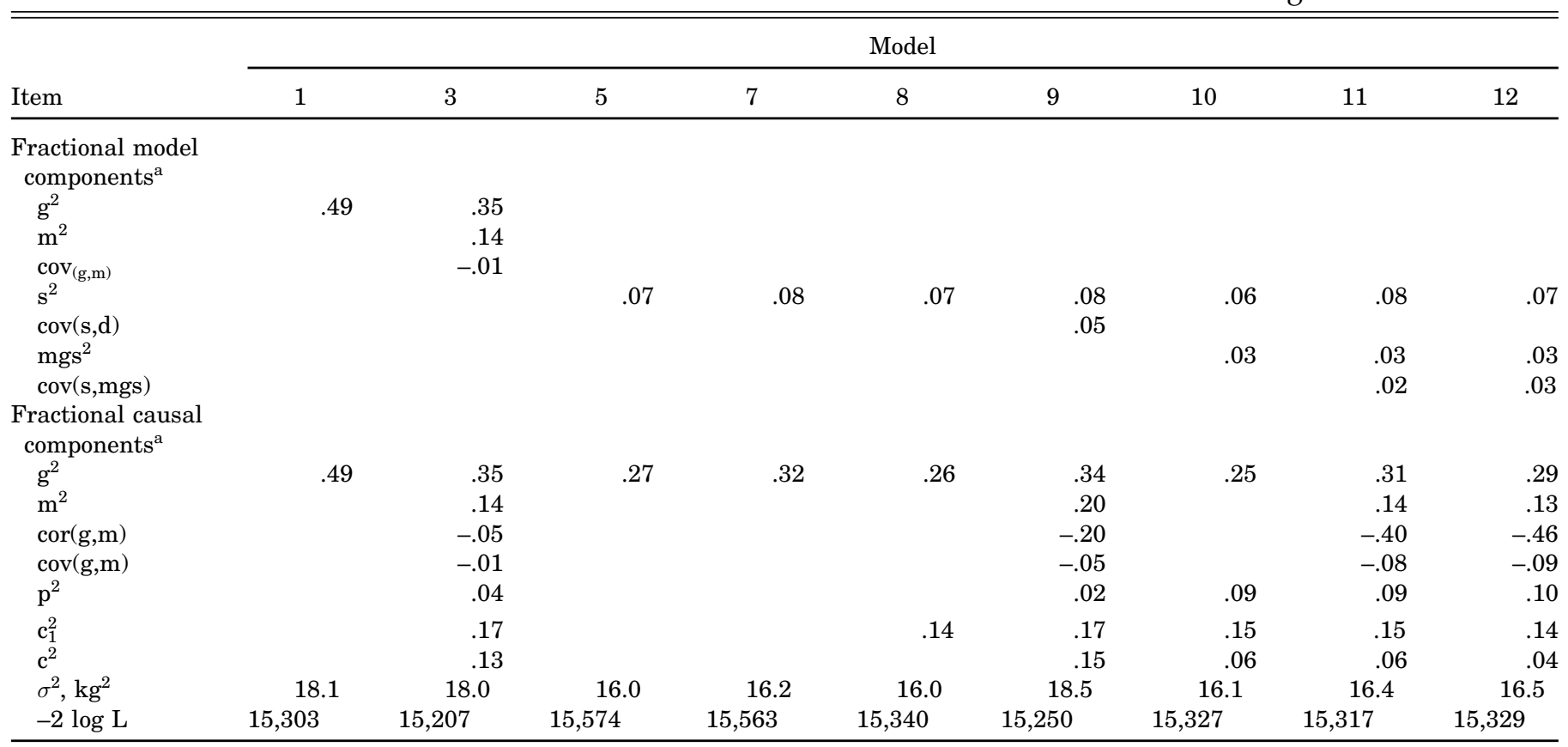

${ }^{\mathrm{a}} \mathrm{g}^{2}=$ direct genetic variance; $\mathrm{m}^{2}=$ maternal genetic variance; $\operatorname{cor}(\mathrm{g}, \mathrm{m})=$ correlation between direct and maternal genetic effects; cov $(\mathrm{g}, \mathrm{m})=$ covariance between direct and maternal genetic effects; $\mathrm{c}^{2}=$ variance of uncorrelated dam effects; $\sigma_{\mathrm{s}}^{2}=$ sire variance; $\mathrm{d}^{2}=$ dam variance; $\operatorname{cov}(\mathrm{s}, \mathrm{d})=$ covarance between sire and dam effects; $\sigma_{\mathrm{mgs}}^{2}=$ maternal grandsire (MGS) variance; $\operatorname{cov}(\mathrm{s}, \mathrm{mgs})=$ covariance between sire and MGS effects; $\mathrm{p}^{2}=$ maternal permanent environmental variance; $\mathrm{c}_{1}^{2}=\sigma_{\mathrm{m}}^{2}+\sigma_{\mathrm{gm}}+\sigma_{\mathrm{p}}^{2} ; \mathrm{c}^{2}=\sigma_{\mathrm{m}}^{2}+\sigma_{\mathrm{gm}} ; \sigma^{2}=$ phenotypic variance; $-2 \log \mathrm{L}=-2 \log$ likelihood (except for a constant).

.35 (full model) to .25 (Model 10). Total maternal variance was similar for Models 3 and 10. The likelihoodratio test was significant $(P<.01)$ for comparison of Models 5 and 10.

Estimates of causal variance components for the full model (Model 3) and the sire-MGS model using relationships through males (Model 11) or using the full relationship matrix as for Model 3 were similar. Direct heritability estimates were .31 for Model 11 and .29 for Model 12. The estimate of maternal heritability was .14 with Model 11 and was similar to the .13 with Model 12. Correlations between genetic and maternal effects were -.40 with Model 11 and -.46 with Model 12 .

The $\mathrm{c}_{1}^{2}$ coefficient (sum of $\sigma_{\mathrm{m}}^{2}+\sigma_{\mathrm{gm}}+\sigma_{\mathrm{p}}^{2}$ divided by total variance) was similar for Models $3,8,10,11$, and 12 , ranging from .14 to .17 , which indicates that those models accounted similarly for maternal effects.

Table 6 shows the product movement and rank correlations between estimated breeding values using Model 3 and using various sire models (Models 5, 7, 9, and 11). The largest correlations were between estimated breeding values and ranks using Model 3 with those using Model 9 followed by correlations with Models 11 and 7 and, finally, Model 5. The correlations are small enough to suggest that sire models may not be adequate for evaluating sires for birth weight if the full animal model can be assumed to be most appropriate.

\section{Weaning Weight}

Table 7 shows estimates of fractional model and causal variance components for weaning weight. The heritability estimates for direct genetic effects decreased from . 35 for Model 1 to .18 for Model 3, indicating that failure to account for maternal effects probably biased the estimate of direct genetic variance with these data. The likelihood-ratio test showed significance $(P<$ .01) between Models 1 and 3 for WWT. With the full model, the estimate of relative variance due to maternal genetic effects was .17, and the estimate of correlation between direct and maternal genetic effects was -.34, in agreement with literature estimates for Herefords (e.g., Koch, 1972).

The comparison between the sire model (Model 5) and the full animal model (Model 3) shows that the heritability estimate for the direct effects dropped

Table 6. Correlations between estimates of breeding values (BV) and ranks from Model 3 and from Models 5, 7, 9, and 11 for birth weight, weaning weight, and yearling weight

\begin{tabular}{lcccc}
\hline \hline Trait/item & Model 5 & Model 7 & Model 9 & Model 11 \\
\hline Birth weight & & & & \\
BV & .76 & .85 & .93 & .89 \\
Rank & .76 & .85 & .93 & .89 \\
Weaning weight & & & & \\
BV & .66 & .79 & .84 & .83 \\
Rank & .61 & .76 & .82 & .81 \\
Yearling weight & & & & \\
BV & .52 & .64 & .85 & .75 \\
Rank & .48 & .62 & .86 & .73 \\
\hline
\end{tabular}


Table 7. Model and causal estimates as fractions of total variance for 205-d weaning weight

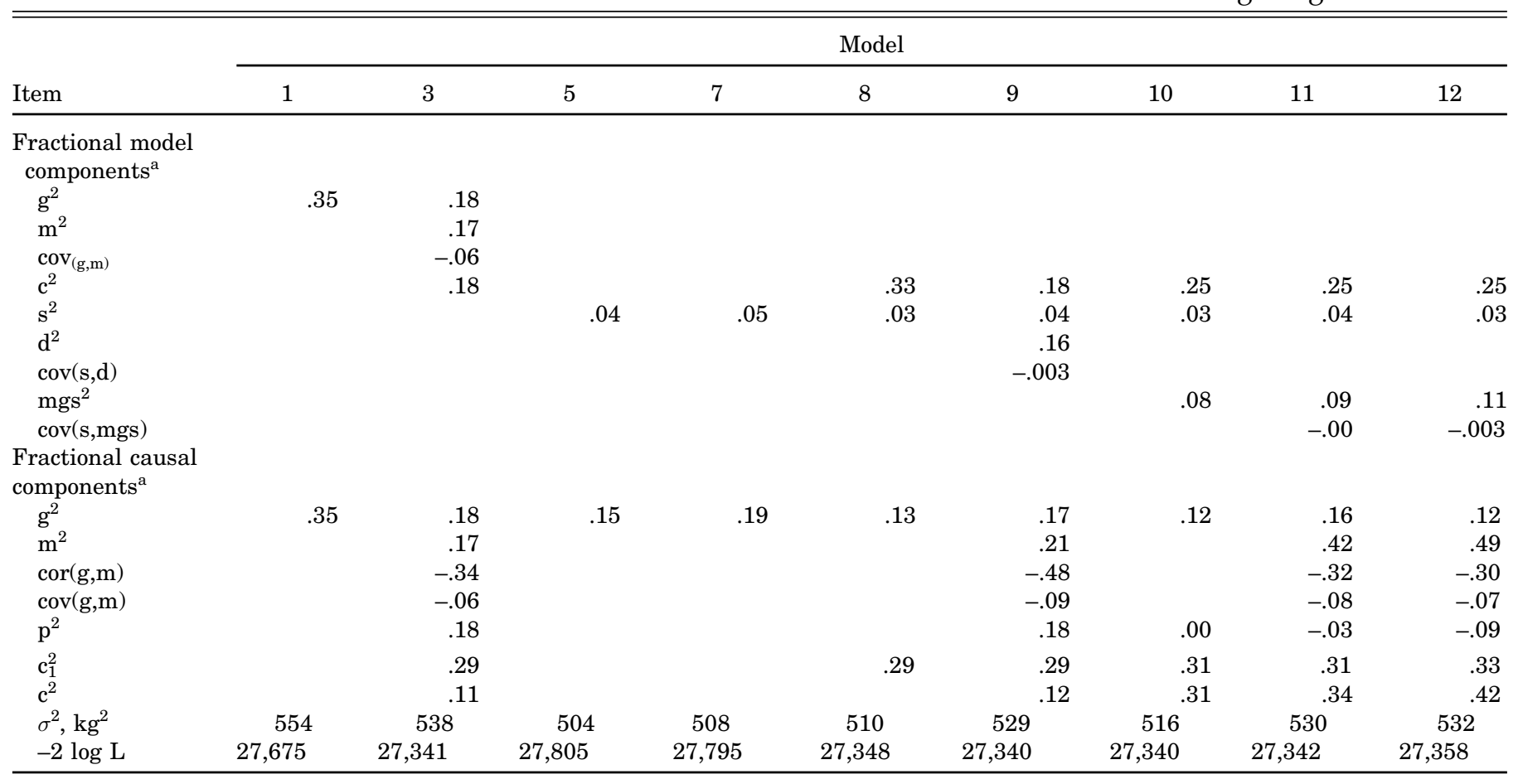

${ }^{\mathrm{a}} \mathrm{g}^{2}=$ direct genetic variance; $\mathrm{m}^{2}=$ maternal genetic variance; $\operatorname{cor}(\mathrm{g}, \mathrm{m})=$ correlation between direct and maternal genetic effects; $\operatorname{cov}(\mathrm{g}, \mathrm{m})=$ covariance between direct and maternal genetic effects; $c^{2}=$ variance of uncorrelated dam effects; $\mathrm{s}^{2}=$ sire variance; $\mathrm{d}^{2}=$ dam variance; $\operatorname{cov}(\mathrm{s}, \mathrm{d})=\operatorname{covariance}$ between sire and dam effects; $\sigma_{\mathrm{mgs}}^{2}=$ maternal grandsire (MGS) variance; $\operatorname{cov}(\mathrm{s}, \mathrm{mgs})=\operatorname{covariance}$ between sire and MGS effects; $\mathrm{p}^{2}=$ maternal permanent environmental variance; $\mathrm{c}_{1}^{2}=\sigma_{\mathrm{m}}^{2}+\sigma_{\mathrm{gm}}+\sigma_{\mathrm{p}}^{2} ; \mathrm{c}^{2}=\sigma_{\mathrm{m}}^{2}+\sigma_{\mathrm{gm}} ; \sigma^{2}=$ phenotypic variance; $-2 \log \mathrm{L}=-2 \log$ likelihood (except for a constant).

slightly from .18 to .15 . The likelihood values showed that Model 3 was a better fit to the data than Model 5.

When relationships were calculated by rules for sire, sire of sire, and maternal grandsire of sire, the sire model (Model 7) resulted in a direct heritability estimate of .19. Compared with Model 5 (sires assumed unrelated), the failure to account for relationships reduced the estimate of heritability, in agreement with Van Vleck and Hudson (1982). Compared with Model 3 , Model 7 showed a slight increase in heritability estimate from .18 to .19. The likelihood-ratio test seemed to show a difference between Models 5 and 7, but it was not significant between Models 5 and 7 . With Model 8 , a sire model (assuming sires unrelated) with a dam effect to account for maternal genetic and permanent environmental effects, the heritability estimate dropped slightly to .13 from .15 with Model 5 and .18 with Model 3. Total estimate of fractional variance due to maternal effects was .29 for both Models 3 and 8 .

Heritability estimate with Model 9 (sire-dam with relationships model, and dam also as uncorrelated random effect) was essentially the same as for the full animal model. The relative maternal genetic variance increased from .17 (full model) to .21 (sire-dam model). Genetic correlations between direct and maternal effects were negative with both models, -.34 for the full model and -.48 for the sire-dam model. These results may indicate slight overestimates of magnitude of variances for maternal effects and of genetic correlation between maternal and direct effect for the sire and dam model compared with a full model. Relative variance due to the sum of all maternal effects was the same for both models, .29, and also for Model 8.

The comparison between Models 3 and 10 (sire model with MGS and dam as uncorrelated random effects) showed that the direct heritability estimate decreased from .18 (Model 3) to .12 (Model 10). The fractions of total variance accounted for by the sum of all maternal effects were similar for both models, but the partition was different.

Compared with Model 3, Model 11 showed for direct heritability a decrease from .18 to .16 and from .18 to .12 for Model 12, and for maternal heritability a large increase from .17 to .42 (Model 11) and to .49 (Model 12). Estimates of correlation between direct and maternal genetic effects were similar for Model 11 (-.32) and for Model $12(-.30)$ with the causal relative variance of maternal environmental effects below the limit of zero, compared to .18 for Model 3.

The total of fractional components of variance and covariance associated with all maternal effects $\left(\sigma_{\mathrm{m}}^{2}+\right.$ $\sigma_{\mathrm{gm}}+\sigma_{\mathrm{p}}^{2}$ divided by phenotypic variance) for Models 8 , 10, 11, and 12 were similar: .29 for Model 8, .31 for Models 10 and 11, and .33 for Model 12.

Correlations of estimated breeding values for direct effects for sires and the rank correlations among solutions from solutions with Model 3 and from solutions with Models 5, 7, 9, and 11 for weaning weight (Table 
6) showed the same pattern as for birth weight. Model 9 solutions were most similar to Model 3. Model 5 solutions were the most different from Model 3, although all sets of correlations were less than the correlations among models for birth weight.

\section{Yearling Weight}

Table 8 shows estimates of fractional model and causal variance components for yearling weight. Comparison of estimates for Models 1 and 3 showed that inclusion of maternal additive and permanent environmental effects decreased the estimate of direct heritability from .36 to .30 , much less than for BWT and WWT, which both had much larger relative estimates of maternal genetic variance. The likelihood-ratio test showed significance $(P<.01)$ between Models 1 and 3 . The estimate of direct-maternal genetic correlation from Model 3 was negative and suggests that an antagonistic relationship carried over from weaning between direct and maternal genetic effects, although the proportional maternal genetic variance was smaller than for weaning weight.

Comparison between the full model (Model 3) and simple sire model (Model 5) shows that the heritability estimate was the same (.30), although the likelihood values showed that Model 3 was a better fit for the data, probably due to accounting for maternal effects.

Compared with the simple sire model (Model 5), the estimate for direct heritability with Model 7 (relationships among sires) increased from .30 to .36 , although the likelihoods were essentially the same. Compared with Model 3, the larger heritability estimate may indicate confounding of sire effects with effects such as dam effects not accounted for by the model, or it may be due to sampling variance of an estimate based on only 160 sires.

With Model 8, a sire model (assuming sires unrelated) with a dam effect to account for maternal genetic and environmental effects, the estimate of direct heritability decreased slightly to .27 as compared to Model 3 .

Compared with the full model, the estimate of direct heritability for Model 9 (sire-dam model with dam also as an uncorrelated random effect) also increased from .30 to .36 , in contrast to BWT and WWT analyses, which showed little difference between full animal and siredam models. Fractional maternal genetic variance increased from .08 to .11. Correlation between genetic direct and maternal effects was negative and changed slightly from -.26 with Model 3 to -.39 for Model 9 .

Comparison of parameter estimates between Models 3 and 10 (sire model considering dam and MGS as uncorrelated random effects) showed a decrease in estimate of direct heritability with Model 10 to .23 from .30. Although the fraction of variance due to sum of all maternal effects was similar for Models 3 and 10 (.16 and .18), the partition led to an unacceptable estimate of relative causal maternal permanent environmental variance for Model 10, -.03.
Comparison of the full animal model and the sireMGS model (Model 11) showed that direct heritability estimate was slightly less with Model $11, .28$, about the same as for Model 8. The heritability of maternal genetic effects was large, .29, and correlation between direct and maternal effects was negative (-.20). The retrieved estimate of fractional variance due to maternal permanent environmental effects decreased from .09 (Model 3) to an unacceptable -.08 (Model 11).

Compared with the full animal model, Model 12 resulted in an increase in direct heritability estimate, from .30 to .35 . Estimates of heritability for maternal effects and of correlation between direct and maternal genetic effects were essentially the same as for Model 11.

Due to the uniqueness of initial results for Models 11 and 12 , Model 12 was also used for separate analyses for records of the two sexes and also for considering measurements on the two sexes as two different traits with a bivariate analysis, using in this case all pedigree relationships as for the full animal model. One plan (Robert M. Koch, personal communication) was to standardize records of males and females with their standard deviations, but this plan was dropped because the standard deviations were nearly equal.

From the separate analysis of males, the estimate of direct heritability using Model 12 was .31, essentially the same as for Model 3 including both sexes. The relative variance for maternal direct effects was similar to estimates with Models 11 and 12, .31, but much larger than for Model 3. Correlation between direct and maternal genetic effects was -.18. However, when females were considered in a separate analysis, the estimate of direct heritability was extremely high, .87 , with a large and negative estimate of genetic correlation between direct and maternal effects, -.59 , and with a relatively large estimate of maternal genetic variance, .26. The results from the female analysis do not seem easy to explain, except for the possibility of sampling variance.

When yearling weights of the sexes were considered as two traits (multiple-trait model), with genotypes expressed in males and in females, the heritability estimates were essentially the same as when males and females were considered separately.

Table 6 shows for yearling weight the correlations and the rank correlations between estimates from Model 3 and Models 5, 7, 9, and 11 for breeding values for sires. The pattern of correlations was the same as for birth and weaning weights, although the correlations were smaller with Models 5, 7, and 11 for yearling weight than for birth and weaning weights.

\section{General Comments}

Sire models generally had lower estimates of heritability of direct effects than full animal or sire and dam models, especially for birth weight and weaning weight. Full animal and sire-dam models gave generally similar estimates. Selection among sires and correspondingly 
Table 8. Model and causal estimates as fractions of total variance for yearling weight

\begin{tabular}{|c|c|c|c|c|c|c|c|c|c|c|c|c|c|}
\hline \multirow[b]{2}{*}{ Item } & \multicolumn{9}{|c|}{ Model } & \multicolumn{2}{|c|}{ Single trait } & \multicolumn{2}{|c|}{ Two traits } \\
\hline & 1 & 3 & 5 & 7 & 8 & 9 & 10 & 11 & 12 & $12 \mathrm{M}$ & $12 \mathrm{~F}$ & $12 \mathrm{M}$ & $12 \mathrm{~F}$ \\
\hline \multicolumn{14}{|c|}{$\begin{array}{l}\text { Fractional model } \\
\text { components }^{\mathrm{a}}\end{array}$} \\
\hline $\mathrm{g}^{2}$ & .36 & .30 & & & & & & & & & & & \\
\hline $\mathrm{m}^{2}$ & & .08 & & & & & & & & & & & \\
\hline $\operatorname{cov}_{(g, m)}$ & & -.04 & & & & & & & & & & & \\
\hline$c^{2}$ & & .12 & & & .22 & .11 & .17 & .15 & .16 & .14 & .18 & .16 & .18 \\
\hline $\mathrm{s}^{2}$ & & & .08 & .09 & .07 & .09 & .06 & .07 & .09 & .08 & .21 & .07 & .20 \\
\hline $\mathrm{d}^{2}$ & & & & & & .12 & & & & & & & \\
\hline $\operatorname{cov}(\mathrm{s}, \mathrm{d})$ & & & & & & .05 & & & & & & & \\
\hline $\mathrm{mgs}^{2}$ & & & & & & & .07 & .07 & .08 & .08 & .05 & .09 & .06 \\
\hline $\operatorname{cov}(\mathrm{s}, \mathrm{mgs})$ & & & & & & & & .02 & .03 & .02 & .03 & .01 & .03 \\
\hline \multicolumn{14}{|c|}{$\begin{array}{l}\text { Fractional causal } \\
\text { components }^{\text {a }}\end{array}$} \\
\hline$g^{2}$ & .36 & .30 & .30 & .36 & .27 & .36 & .23 & .28 & .35 & .31 & .87 & .28 & .82 \\
\hline $\mathrm{m}^{2}$ & & .08 & & & & .11 & & .29 & .28 & .31 & .26 & .37 & .29 \\
\hline $\operatorname{cor}(\mathrm{g}, \mathrm{m})$ & & -.26 & & & & -.39 & & -.20 & -.19 & -.18 & -.59 & -.24 & -.53 \\
\hline $\operatorname{cov}(\mathrm{s}, \mathrm{mgs})$ & & -.04 & & & & -.08 & & -.06 & -.06 & -.06 & -.28 & -.08 & -.26 \\
\hline $\mathrm{p}^{2}$ & & .12 & & & & .11 & -.03 & -.08 & -.07 & -.10 & .04 & -.12 & .01 \\
\hline $\mathrm{c}_{1}^{2}$ & & .16 & & & .16 & .14 & .18 & .15 & .15 & .15 & .02 & .17 & .56 \\
\hline$c^{2}$ & & .04 & & & & .03 & .22 & .23 & .08 & .05 & -.02 & .29 & .55 \\
\hline$\sigma^{2}, \mathrm{~kg}^{2}$ & 882 & 871 & 816 & 830 & 816 & 862 & 822 & 957 & 866 & 974 & 836 & 972 & 834 \\
\hline$-2 \log \mathrm{L}$ & 1,040 & 939 & 1,140 & 1,135 & 963 & 934 & 923 & 903 & 928 & - & - & - & - \\
\hline
\end{tabular}

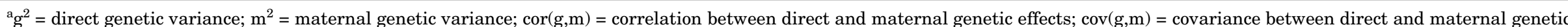

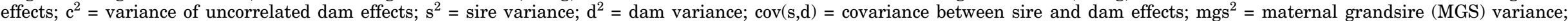

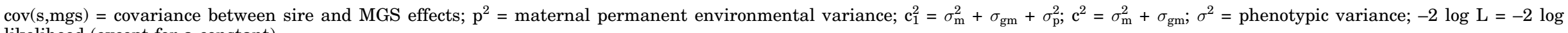
likelihood (except for a constant). 
lower sire variances could explain these results. Animal model estimates might be inflated by dominance or epistatic effects.

For YWT, Models 11 and 12 had much larger estimates of variance components for maternal genetic effects than for Model 3, similar to the pattern of WWT. This is not a surprise, considering the small gain from weaning to yearling weight, especially for females. Considering weights as two traits depending on sex gave essentially the same estimates as when males and females were considered separately.

The relatively small correlations and correspondingly small rank correlations between estimates of breeding values from sire models with solutions from animal models indicate that the use of sire models would result in less genetic improvement from selection than use of a full animal model, if the full animal model can be assumed to provide the best estimates of genetic parameters.

\section{Implications}

Sire models have lower estimates of heritability for direct effects than full animal or sire and dam models, especially for birth weight and weaning weight. Full animal and sire-dam models provide similar estimates. Selection among sires and lower sire variances could explain this. For yearling weight, our Models 11 and 12 produce greater estimates of variance components for maternal genetic effects than our Model 3, which is not a surprise considering the small gain from weaning to yearling weight. Considering sex as two traits produces essentially the same estimates as when males and females are considered separately. The low correlation for estimates of transmitting ability and the correspondingly low correlation for sire models with animal solutions indicate that use of such models would result in less genetic improvement than use of a full animal model.

\section{Literature Cited}

Boldman, K. G., L. A. Kriese, L. D. Van Vleck, C. P. Van Tassell, and S. D. Kachman. 1995. A manual for use of MTDFREML. A set of programs to obtain estimates of variances and covariance (DRAFT). p 114. USDA, ARS, Washington, DC.

de Boer, I.J.M., and I. Hoeschele. 1993. Genetic evaluation methods for populations with dominance and inbreeding. Theor. Appl. Genet. 86:245-258.

Dobson, A. J. 1990. An Introduction to Generalized Linear Models. p 57. Chapman and Hall, New York.

Garrick, D. J., E. J. Pollak, R. L. Quaas, and L. D. Van Vleck. 1989. Variance heterogeneity in direct and maternal weight traits by sex and percent purebred for Simmental-sired calves. J. Anim. Sci. 67:2515-2528.

Graser, H.-U., S. P. Smith, and B. Tier. 1987. A derivative-free approach for estimating variance components in animal models by restricted maximum likelihood. J. Anim. Sci. 64:1362-1370.

Henderson, C. R. 1975. Inverse of a matrix of relationships due to sires and maternal grandsires. J. Dairy Sci. 58:1917-1921.

Koch, R. M. 1972. The role of maternal effects in animal breeding: VI. Maternal effects in beef cattle. Anim. Breed Abstr. 35:1316-1323.

MacNeil, M. D., J. J. Urick, S. Newman, and B. W. Knapp. 1992. Selection for postweaning growth in inbred Hereford cattle: The Fort Keogh, Montana Line 1 example. J. Anim. Sci. 70:723-733.

Meyer, K. 1989. Restricted Maximum Likelihood to estimate variance components for animal models with several random effects, using a derivative-free algorithm. Genet. Sel. Evol. 21:317-340.

Meyer, K. 1993. Estimates of direct and maternal correlations among growth traits in Australian beef cattle. Livest. Prod. Sci. 38:91-105.

Quaas, R. L. 1976. Computing the diagonal elements and inverse of a large numerator relationship matrix. Biometrics 32:949-953.

Robison, O.W. 1981. The influence of maternal effects on the efficiency of selection; A review. Livest. Prod. Sci. 8:121-137.

Smith, S. P., and A. Mäki-Tanila. 1990. Genetic covariance matrices and their inverses for models allowing dominance and inbreeding. Genet. Sel. Evol. 22:65-91.

Van Vleck, L. D., and G.F.S. Hudson, 1982. Relationships among sires in estimating genetic variances. J. Dairy Sci. 65:1663-1665.

Waldron, D. F., C. A. Morris, R. L. Baker, and D. L. Johnson. 1993. Maternal effects for growth traits in beef cattle. The covariance between relatives for characters composed of components contributed by related individuals. Livest. Prod. Sci. 34:57-70. 